\title{
Viability rice seeds with different levels of antioxidants
}

\author{
Yulia Goncharova ${ }^{1,3, *}$, Olesya Bragina ${ }^{1}$, Sergey Goncharov ${ }^{2}$, and Evgeniy Kharitonov ${ }^{1}$ \\ ${ }^{1}$ FGBNU "Federal Research Center for Rice", 350921 Krasnodar, Belozerny 3, RF \\ ${ }^{2}$ Kuban State Agrarian University, 350000 Krasnodar, RF \\ ${ }^{3}$ OOO "Aratai", "Skolkovo", 143026 Moscow, RF
}

\begin{abstract}
Total content of anthocyanidin glucosides varies greatly among different black varieties (79.5$473.7 \mathrm{mg} / 100 \mathrm{~g}$ ) and red rice (7.9-34.4 mg / $100 \mathrm{~g}$ ). Shown up to 20 times higher content of antioxidants in black rice varieties, compared with white grain, as well as their up to 45 times higher antioxidant activity compared with many other crop. In terms of antioxidant content, black rice is not inferior even to such well-known sources as blueberries and black currants, but much cheaper. The role of phenolic acids as substances increasing adaptability to various stresses is considered. The presence of anthocyanidin glucoside is also useful for the plants themselves at the cellular level, normalizing metabolic processes in response to various unfavorable abiotic influences, thereby increasing their adaptability to stress and the viability of seeds. The objectives of the study were to identify germination rate of rice seeds various groups of ripeness, color of pericarp, shape and weight of caryopsis. Seeds of varieties stored in uncontrolled temperature conditions three years. Every year, a study germination of seeds all groups was carried out. 100 grains of each variety were placed in Petri dishes in three repetitions and germinated in a thermostat at a temperature of $29^{\circ} \mathrm{C}$ for 7 days, after which the percentage of germinated seeds was calculated. Our research showed a high germination rate seeds of red and black varieties. Them viability significantly exceeded white-grain varieties various groups of ripeness, weight and shape of caryopsis on second and third years of storage. If during the first year the differences in germination between most varieties are not reliable, then in the third year the white-grain varieties significantly inferior in vitality varieties of other groups.
\end{abstract}

\section{Introduction}

The beneficial effects of antioxidants on human health prompted breeders working with various crops to increase their content in newly created varieties. Varieties with increased content of anthocyanidin glucosides have already been created for such crops as spring wheat [1], blueberries [2], purple sweet potatoes [3], purple and red cabbage [4]. Black-grain and redgrain rice varieties have been known for a long time, but only recently there have been studies confirming their healing properties. Since ancient times, they have been used as medicines or tannins. However, mechanism of their action remained poorly understood. Studies have shown that manifestation of various pharmacological effects of black and red rice, including antioxidant, antiinflammatory, antitumor, are largely associated with the action of anthocyanidin glucoside [5,6,7]. It also induced apoptosis of leukemic cells, various neuroprotective and immunomodulatory effects $[8,9,10]$. Traditional Chinese medicine has used red rice to treat kidney problems, anemia, diabetes, and improve vision and blood circulation $[11,12,13]$.

Anthocyanins, natural useful dyes from pink to purple, can be an excellent alternative to synthetic dyes [14]. The total content of anthocyanidin glucosides varies greatly among different black varieties (79.5$473.7 \mathrm{mg} / 100 \mathrm{~g}$ ) and red rice $(7.9-34.4 \mathrm{mg} / 100 \mathrm{~g}$ ) [15.16]. $85 \%$ of rice varieties in the world have a white pericarp, the rest are colored black, red or purple [13]. It is necessary to distinguish red-grain rice varieties, more productive and not shattering, and wild-growing (weed), the latter is usually tall, early maturing, shattering - the main weed in many farms in the world. Cultivated black and red-grain rice varieties are not inferior to white-grain rice in terms of yield and their height also does not differ from varieties with white pericarp. The presence of anthocyanidin glucoside is also useful for the plants themselves at the cellular level, normalizing metabolic processes in response to various unfavorable abiotic influences, thereby increasing their adaptability to stress and the viability of seeds [17].

The aim of work is to study the change viability of rice seeds depending on content of antioxidants and other characteristics of the variety.

\section{Material and methods}

As a material for research, we used 10 regionalized and promising varieties of Russian breeding from collection Federal State Budgetary Scientific Institution "FNTs

\footnotetext{
* Corresponding author: yuliya_goncharova_20@mail.ru
} 
Table 1. Germination of rice seeds various groups of ripeness, color of pericarp, shape and weight of caryopsis.

\begin{tabular}{|c|c|c|c|}
\hline Varieties & 2018 year & 2019 year & 2020 year \\
\hline \multicolumn{4}{|c|}{ Early-maturing } \\
\hline Snephok (coarse) & 96.3 & 82.4 & 66.2 \\
\hline Novator (short-grain) & 89.2 & 51.4 & 33.3 \\
\hline \multicolumn{4}{|c|}{ Long-grain } \\
\hline Ivushka & 98.6 & 86.4 & 54.2 \\
\hline Svetlana & 99.7 & 89.1 & 57.8 \\
\hline \multicolumn{4}{|c|}{ Black-grain } \\
\hline Smuglanka (early maturing) & 96.3 & 76.2 & 65.9 \\
\hline Mulatka (mid-late maturing) & 100 & 98.3 & 95.1 \\
\hline \multicolumn{4}{|c|}{ Red-grain } \\
\hline Aurora (long grain) & 99.8 & 91.3 & 87.3 \\
\hline Assol (medium grain) & 97.8 & 86.4 & 73.1 \\
\hline \multicolumn{4}{|c|}{ Coarse-grain } \\
\hline Krepish (weight a.d. 1000 grains $36.2 \mathrm{~g}$ ) & 99.4 & 87.2 & 67.2 \\
\hline Kazachek (weight a.d. 1000 grains 32.6 g) & 97.3 & 83.1 & 59.3 \\
\hline
\end{tabular}

Rice". Among them were varieties of different quality: blask-grain, red-grain, large-grain, long-grain, with various culinary and technological properties. The objectives of the study were to identify germination rate of rice seeds various groups of ripeness, color of pericarp, shape and weight of caryopsis. Seeds of studied varieties were stored from 2017 to 2020 year under uncontrolled conditions. That is, they were exposed to both high and low temperatures throughout the year. Every year, a study germination of seeds all groups was carried out. To do this, 100 grains of each variety were placed in Petri dishes in three repetitions and germinated in a thermostat at a temperature of $29^{\circ} \mathrm{C}$ for 7 days, after which the percentage of germinated seeds was calculated.

\section{Results and discussion}

Our research showed a high germination rate seeds of red-grain and black-grain varieties. The seeds of varieties with colored pericarp stored in uncontrolled temperature conditions second and third years of storage significantly exceeded the white-grain varieties of various groups of ripeness, weight and shape of the caryopsis in second and third years of storage (Table 1, Figure 1).

If during the first year the differences in germination between most varieties are not reliable, then in the third year the white-grain varieties significantly inferior in vitality to varieties of other groups.

Antioxidant activity is not measured directly, it is determined by monitoring the oxidation state. Currently, a number of methods are used to determine antioxidant activity, among them: chemiluminescent (FICA), DPPH method - CP colorimetry based on the reaction of DPPH (2,2-diphenyl-1-picrylhydrazyl) dissolved in methanol $[18,19]$. The color of the pericarp is mainly related to the content of phenolic compounds: the darker pericarp, the more polyphenols (flavonoids and other antioxidants) it contains. The reddish brown or dark brown color of plant seeds is due to flavonoid compounds proanthocyanidins and flobaphenes. Red rice is

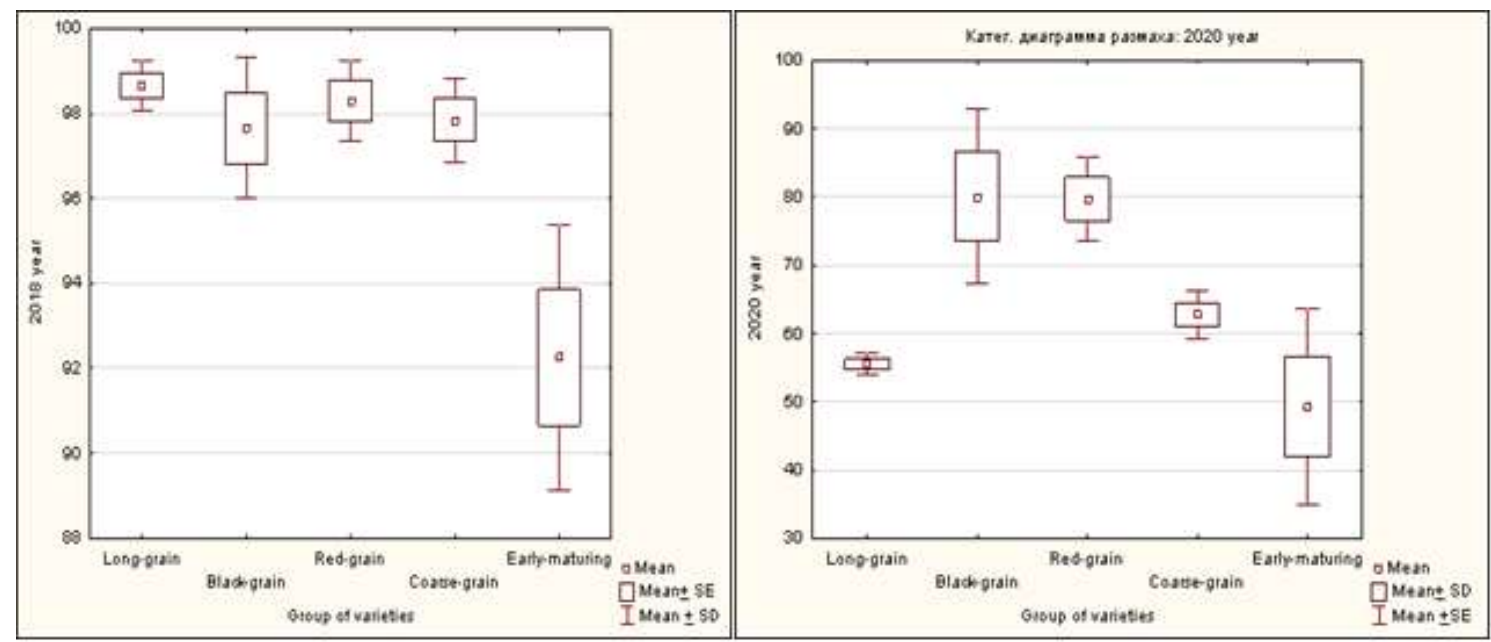

Fig. 1. Germination of rice seeds of various groups of ripeness, color of the pericarp, shape and weight of caryopsis in the first year after harvesting and in the third year. 
Table 2. Anthocyanin content in raw and cooked rice and percentage of loss (Kushwaha, 2016).

\begin{tabular}{|c|c|c|c|}
\hline Antioxidant & Raw & Risotto & Boiled with excess water \\
\hline Cyanidin3-0-glucoside & $255.7 \pm 4.2$ & $184.6 \pm 13.7(-27.8 \%)$ & $96.2 \pm 0.6(-62.4 \%)$ \\
\hline Peonidin3-0-glucoside & $50.8 \pm 0.7$ & $28.2 \pm 0.6(-44.4 \%)$ & $15.5 \pm 0.9(-69.5 \%)$ \\
\hline Cyanidin3-0-rutinoside & $7.5 \pm 0.1$ & $6.51 .0(-13.0 \%)$ & $1.9 \pm 0.4(-74.7 \%)$ \\
\hline Peonidin3-0-rutinoside & $1.3 \pm 0.1$ & $0.8 \pm 0.2(-38.5 \%)$ & $0.5 \pm 0.0(-61.5 \%)$ \\
\hline Peonidin -0-diglucoside & $18.6 \pm 0.3$ & $14.4 \pm 07(-22.6 \%)$ & $5.4 \pm 0.3(-71.0 \%)$ \\
\hline Total & $333.9 \pm 0.4$ & $234.5 \pm 14.1(-29.8 \%)$ & $119.5 \pm 1.2(-64.2 \%)$ \\
\hline
\end{tabular}

Table 3. The content of antioxidants in plants (Yao et al, 2009).

\begin{tabular}{|c|c|c|c|}
\hline Sample & Amount of phenols & Amount of anthocyanins & Antiradical activity \\
\hline Red rice & $0.102 \pm 0.011$ & $0.054 \pm 0.013$ & $1.631 \pm 0.152$ \\
\hline Black corn & $1.112 \pm 0.091$ & $0.313 \pm 0.013$ & $1.684 \pm 0.193$ \\
\hline Dark colored barley & $0.461 \pm 0.042$ & $0.271 \pm 0.052$ & $2.212 \pm 0.371$ \\
\hline Black grain soybeans & $0.751 \pm 0.063$ & $0.191 \pm 0.024$ & $4.591 \pm 0.272$ \\
\hline Bran dark-colored soybeans & $5.264 \pm 0.422$ & $1.631 \pm 0.033$ & $13.943 \pm 4.864$ \\
\hline Black rice & $8.581 \pm 0.563$ & $3.834 \pm 0.041$ & $73.471 \pm 4.634$ \\
\hline
\end{tabular}

characterized by the presence of proanthocyanidins, while black rice is characterized by the accumulation of anthocyanins, mainly cyanidin-3-glucoside and peonidin-3-glucoside (Table 2).

Red rice contains phenolic compounds in the range of $165.8-731.8 \mathrm{mg} / 100 \mathrm{~g}$. The accumulation of anthocyanins in black rice in glutinous varieties varies from 262 to $2539 \mathrm{mg} / 100 \mathrm{~g}$ [20]. It should be noted that the maximum retention of nutrients contained in rice ensures its preparation using a method in which all the water is absorbed by the rice mass and all antioxidants remain in the finished dish [21]. Peroxidase is also part of the plant antioxidant complex. We have evaluated the complex activity of phenol oxidizing peroxidases by the oxidation reaction of guaiacol by a protein extract from rice seedlings. According to the research results, this type of peroxidases is a key antioxidant enzyme in rice seedlings at the presented stage of development. The median was $8.63 \mathrm{AU} / \mathrm{g}$ protein. The maximum activity of the enzyme was found in the cultivars with stained pericarp Day / Night, Mulatka and Mavr. The amount of phenols in rice varieties with black pericarp exceeds that in red-grain ones up to 7.9 times, and in the amount of anthocyanins up to 59 times, which allows them to demonstrate more than 40 times increased activity reducing the content of radicals (Table 3) [22].

According to above data, the main feature of rice varieties with colored pericarp is a higher content of antioxidants. The darker pericarp, the higher it is. The high viability of seeds of black-grain and red-grain varieties revealed by us can be used to adjust the seeding rates during sowing and serve as an indirect assessment of the antioxidant activity of the variety.

\section{Conclusion}

1. Total content of anthocyanidin glucosides varies greatly among different black varieties (79.5-473.7 mg / $100 \mathrm{~g})$ and red rice (7.9-34.4 mg / $100 \mathrm{~g})$. Shown up to 20 times higher content of antioxidants in black rice varieties, compared with white grain, as well as their up to 45 times higher antioxidant activity compared with many other crop.

2. Showed a high germination rate seeds of red and black varieties.

3. During the first year the differences in germination between most varieties are not reliable, then in the third year the white-grain varieties significantly inferior in vitality to varieties of other groups.

4. The high viability of seeds of black-grain and redgrain varieties revealed by us can be used to adjust the seeding rates during sowing and serve as an indirect assessment of the antioxidant activity of the variety.

This work was financially supported by the Russian Science Foundation No. 19-16-00064.

\section{References}

1. D.C. Knievel, A.A. Esm, , I. Rabalski, T. Nakamura, and P. Hucl, J. Cereal Sci., 50, 113-120 (2009)

2. X. Li, H. Liu, L. Liv, H. Yan, and Y. Yuan, Int. J. Food Sci. Technol., 53, 147-155 (2018)

3. T.Tensiska,H. Marta, Y. Cahyanaand N.S. Amirah, KnE Life Sci. 2, 482-493 (2017)

4. Q. Zhu, Yu.S. Zeng, H, Liu, H. Wang and Z.Yang, et al, Mol. Plant, 10, 918-929 (2017)

5. S. Zafra-Stone, T. Yasmin, M. Bagchi, A. Chatterjee, J.A., Vinson, and D. Bagchi, Mol. Nutr. Food Res., 51, 675-683(2007)

6. J.Y. Lin, C.Y. Li, and I.F. Hwang, Food Chem., 109, 771-781 (2008)

7. L.S. Wang G.D. Stoner, Cancer Lett., 269, 281-290 (2008)

8. Y.C. Chang, H.P.Huang, J.D. Hsu, S.F. Yang, and C.J. Wang, Toxicol. Appl. Pharmacol., 205, 201212 (2005)

9. T.H. Kang, J.Y. Hur, H.B. Kim, J.H. Ryu, and S.Y Kim, Neurosci. Lett., 391, 122-126(2006) 
10. V. Taverniti, D. Fracassetti, B.C. Del, C. Lanti, M. Minuzzo and D. Klimis-Zacas, et al., J. Agric. Food Chem., 62, 8346-8351(2014)

11. G.F. Deng, X.R. Xu,Y. Zhang, D. Li, R.Y. Gan, and H.B. Li, Crit. Rev. Food Sci. Nutr., 53, 296306(2013)

12. B. Min A.M. Clung, and M.H. Chen, J. Food Sci., 76, 117-126 (2011)

13. P. Goufo and H. Trindade, Food Sci. Nutr., 2, 75104 (2014)

14. Y. Zhang, E. Butelli, and C. Martin, Plant Biol., 19, 81-90 (2014)

15. X.Q. Chen, N. Nagao, T. Itani, and K. Irifune, Food Chem., 135, 2783-2788 (2012)

16. M.H. Chen, A.M. Clung and C.J. Bergman, Data in Brief, 8, 6-13 (2016)

17. L.J. Zhou, Y.Y. Li, R.F. Zhang, C.L Zhang, X.B. Xie, C. Zhao and Y.J. Hao, Plant Cell Environ. 40, 2068-2080 (2017)

18. R.M. Patel, Int. J. Sci. Res., 2, 426- 428 (2013)

19. X. Mei,C. Yiand G. Huang, Mini Rev. Med. Chem., 17, 863-868 (2017)

20. M.W. Zhang, R.F. Zhang, F.X. Zhang and R.H. Liu, J. Agric. Food Chem., 58, 7580-7587 (2010)

21. U.K. Kushwaha, Black Rice. Springer International Publishing Switzerland. 206 (2016)

22. Y. Yao, S. Wei, Z. Mengjie, R. Guixing J. Agric. Food Chem (2009). 